\title{
Boosting Wnt activity during colorectal cancer progression through selective hypermethylation of Wnt signaling antagonists
}

\author{
Ana-Luisa Silva', Sarah N Dawson ${ }^{2,3}$, Mark J Arends $^{1,4}$, Kiran Guttula ${ }^{1}$, Nigel Hall, Ewen A Cameron ${ }^{6}$,
} Tim H-M Huang ${ }^{7}$, James D Brenton ${ }^{3}$, Simon Tavaré ${ }^{3}$, Mariann Bienz ${ }^{8}$ and Ashraf EK Ibrahim ${ }^{1,8^{*}}$

\begin{abstract}
Background: There is emerging evidence that Wnt pathway activity may increase during the progression from colorectal adenoma to carcinoma and that this increase is potentially an important step towards the invasive stage. Here, we investigated whether epigenetic silencing of Wnt antagonists is the biological driver for this increased Wnt activity in human tissues and how these methylation changes correlate with MSI (Microsatelite Instability) and CIMP (CpG Island Methylator Phenotype) statuses as well as known mutations in genes driving colorectal neoplasia.

Methods: We conducted a systematic analysis by pyrosequencing, to determine the promoter methylation of CpG islands associated with 17 Wnt signaling component genes. Methylation levels were correlated with MSI and CIMP statuses and known mutations within the APC, BRAF and KRAS genes in 264 matched samples representing the progression from normal to pre-invasive adenoma to colorectal carcinoma.

Results: We discovered widespread hypermethylation of the Wht antagonists SFRP1, SFRP2, SFRP5, DKK2, WIF1 and SOX17 in the transition from normal to adenoma with only the Wht antagonists SFRP1, SFRP2, DKK2 and WIF1 showing further significant increase in methylation from adenoma to carcinoma. We show this to be accompanied by loss of expression of these Wnt antagonists, and by an increase in nuclear Wnt pathway activity. Mixed effects models revealed that mutations in APC, BRAF and KRAS occur at the transition from normal to adenoma stages whilst the hypermethylation of the Wnt antagonists continued to accumulate during the transitions from adenoma to carcinoma stages.
\end{abstract}

Conclusion: Our study provides strong evidence for a correlation between progressive hypermethylation and silencing of several Wnt antagonists with stepping-up in Wnt pathway activity beyond the APC loss associated tumour-initiating Wnt signalling levels.

\section{Background}

Colorectal cancer (CRC) is the second most common cause of cancer-related death in the UK accounting for approximately $10 \%$ of all cancer deaths [1]. Known genetic and epigenetic aberrations drive the formation of a benign adenoma, and its progression to full-blown colorectal carcinoma [2-4]. In particular, $>90 \%$ of CRC exhibit mutations in the Adenomatous polyposis coli (APC) gene and in other Wnt signaling components that

\footnotetext{
* Correspondence: aeki2@cam.ac.uk

'Department of Pathology, Division of Molecular Histopathology, University of Cambridge, Addenbrooke's Hospital, Hills Road, Cambridge CB2 2QQ, UK ${ }^{8}$ MRC, Laboratory of Molecular Biology, Hills Road, Cambridge CB2 OQH, UK Full list of author information is available at the end of the article
}

result in hyperactivation of the Wnt pathway, and these mutations are the earliest known genetic alterations, indicating that they represent the initiating event in the path to CRC $[2,5,6]$. APC is a crucial negative regulator of the Wnt pathway: as a component of the cytoplasmic Axin degradasome complex, APC promotes the proteasomal degradation of the Wnt effector $\beta$-catenin; if this complex is dysfunctional as a consequence of mutational inactivation of $A P C, \beta$-catenin accumulates to high levels and translocates into the nucleus where it operates a transcriptional switch [7]. One of its direct transcriptional targets is $c-M Y C$, whose product is pivotal in driving malignancy in both mice and humans $[8,9]$. 
The role of Wnt signaling in initiating CRC is therefore well documented. However, it is less clear whether hyperactive Wnt signaling is also required for the progression from adenoma to carcinoma. Recent evidence suggests that this may be the case, based on xenograft models in mice and on the observation that $\beta$-catenin accumulates to high levels in CRC samples [10]. Similarly, our own data revealed that the levels of nuclear $\beta$-catenin tend to be elevated in early adenomas, but show a further surge in levels in carcinomas, indicating that the Wnt signaling levels increase during cancer progression [11]. Furthermore, epigenetic inactivation of extracellular Wnt signaling antagonists has also been observed in colorectal carcinomas, which could boost Wnt signaling to levels above those caused by the initial mutational inactivation of $A P C$ [12]. All these are indications that the level of Wnt signaling increases from the adenoma to the carcinoma stage, implying that the sustained (or increased) activity of $\beta$-catenin could be critical throughout CRC progression.

Epigenetic silencing by DNA hypermethylation of associated $\mathrm{CpG}$ islands is a common mechanism by which genes are inactivated during cancer development. In CRC, epigenetic silencing has been observed not only for negative regulators of Wnt signaling upstream in the pathway, such as the extracellular Wnt inhibitors SFRP1, SFRP2, SFRP3, SFRP4, SFRP5, WIF1, DKK1 and DKK3 [12-19] and DACT3 [20] but also for negative regulators acting further downstream in the pathway, including $A P C$ [21], AXIN2 [22], CDH1 [23] and SOX17 [24]. However, none of these studies entailed a systematic and comprehensive characterization of the synchronous changes of DNA methylation patterns of Wnt antagonists and particularly how these changes affect Wnt signalling transcriptional output through the neoplastic progression from the pre-invasive adenoma stage to the invasive carcinoma stage. In addition, no data is available on: (i) the association of the methylation changes of Wnt antagonists with microsatalite instability (MSI)/CpG island methylator phenotype (CIMP) statuses nor (ii) its relationship to known mutations in genes involved in the early progression of colorectal neoplasia.

We thus set out to analyze systematically the CpG methylation patterns at gene promoters of $17 \mathrm{Wnt}$ signaling components (Additional file 1) and correlate these patterns with expression levels of nuclear $\beta$-catenin and two well-established Wnt target genes (AXIN2 and $c-M Y C)$. In addition, we examined the correlation of the methylation patterns of these Wnt genes with MSI/CIMP statuses, the presence of known mutations within $A P C, B R A F$ and $K R A S$, in a large set of matching normal, hyperplastic or adenomatous polyps, primary and metastatic adenocarcinoma tissue samples. Finally, we asked if the identified patterns of methylation of these Wnt genes impact patients' survival.

\section{Methods}

\section{Clinical sample collection}

Two independent sample sets were collected from colectomy surgical specimens (the clinicopathological characteristics are summarised in Additional file 2). The first set of samples $(\mathrm{CRC} 1, \mathrm{n}=86)$ was obtained from $48 \mathrm{pa}-$ tients with invasive colorectal primary carcinoma with or without evidence of metastatic cancer deposits. The CRC1 sample set comprised normal colonic mucosa $(n=20)$, primary $(\mathrm{n}=51)$ and liver metastatic $(\mathrm{n}=15)$ adenocarcinomas. The second set (CRC2) comprised 172 samples from a set of 49 patients presenting with synchronous adenoma and invasive carcinoma. Normal tissue samples $(\mathrm{n}=73$ ) were collected at $5 \mathrm{~cm}$ and $20 \mathrm{~cm}$ (where available) away from the carcinoma and were defined as highrisk normal mucosa (HRN), samples from hyperplastic polyps $(n=13)$, adenomatous polyps $(n=39)$ and primary adenocarcinoma $(n=47)$ were also collected. For comparison, we collected normal mucosa from patients undergoing colectomy for diverticular disease $(n=6)$ who had no previous or present history of CRC. These samples were defined as low-risk normal mucosa (LRN). The histological features and cellularity of all tissue samples were assessed by microscopic examination of tissues sampled immediately adjacent to the site of sampling fresh tissues by a histopathologist with interest in CRC (AEKI). Samples were collected within the Histopathology Department and the Tissue Bank facility within Addenbrooke's Hospital (Cambridge, UK) and a subset of $\mathrm{CRC} 1$ cases $(\mathrm{n}=37)$ was obtained from Ohio State University (OSU) where colonic normal, primary and metastatic adenocarcinoma tissue samples were microdissected. Ethical approval for all the work conducted was obtained from both OSU institutional review board and Cambridgshire local research ethics committee (LREC ref. 04/Q0108/125 and 06/ Q0108/307). Written informed consent was obtained from the patient for the publication of this report and any accompanying images.

\section{DNA extraction and bisulfite modification}

High molecular weight DNA was isolated using a proteinase $\mathrm{K} / \mathrm{phenol}$ extraction method. Sodium bisulfite conversion of DNA was performed using the EZ DNA Methylation-Gold Kit (ZymoResearch, Cambridge, UK), following the manufacturer's protocol.

\section{Total RNA extraction and real-time PCR}

Tissue samples were left in RNAlater-ICE at $-20^{\circ} \mathrm{C}$ for at least 24 hours prior to extraction. RNA was extracted using both chloroform and column based protocols as described in Additional file 2. Quality and quantity of the extracted RNA was verity before storage at $-80^{\circ} \mathrm{C}$. Full details of cDNA synthesis and Real-Time Quantitative PCR (qRT-PCR) are described in Additional file 3. 
We used the Pfaffl method to calculate the expression fold change [25].

\section{Pyrosequencing assays}

Bisulfite-modified DNA was amplified by PCR in a $50 \mu \mathrm{l}$ reaction volume, using the primers described in Additional file 4 and reagents supplied by Applied Biosystems. A $40 \mu \mathrm{l}$ aliquot of each PCR product was used to perform the pyrosequencing reaction following the manufacturer's protocol and as previously described [26]. Negative controls recommended by the manufacturer were used, as well as positive controls that included (i) DNA in vitro methylated using SssI CpG Methyltransferase (New England Biolabs, Hitchin, UK) following the manufacturer's instructions, (ii) hypomethylated DNA, generated through PCR and a (iii) mixture of equal volumes of the above methylated and unmethylated controls. The methylation quantification was analysed by Pyro Q-CpG Software (Biotage, Uppsala, Sweden).

\section{MSI, APC, BRAF, KRAS mutations and CIMP assessment}

MSI, BRAF and CIMP status of the tumours had been previously reported [14]. Mutational analysis of $A P C$ [27] and $K R A S$ [28] were as previously reported.

\section{Statistical analysis}

A modified version of the $R$ package ALL was used to generate image plots of the methylation data within the $R$ statistical environment. We used the package $K m L$ [29] within the $R$ statistical environment [30] to identify the clusters of the trajectories of methylation changes during colorectal neoplastic progression.

Survival analysis was performed using the st functions in Stata 11 [31]. A Cox regression was used to examine the association between survival and average DNA methylation, age, sex, pTMN stage, CIMP and MSI status, and calculate the hazard ratio and the risk of death associated with each variable. The average percentage methylation and age were used as continuous variables and sex, pTMN stage, CIMP and MSI statuses as categorical variables in the Cox regression. The risk of death was first examined by univariable Cox regression and then by multivariable Cox regression to adjust the hazard ratio of one variable in the presence of other variables in the multivariable model. To determine the best predictors of survival a multivariable Cox regression model was constructed based only on the continuous variables plus CIMP and MSI statuses using the stepwise selection method with a $p$ (entry) $=0.049$ and $p($ removal $)=0.05$. Log-rank tests were performed and Kaplan-Meier curves constructed based on the significant variables in the multivariable Cox regression model and used to show the survival patterns of patients depending on the status of these variables. The cut-off used to define high and low methylation for these two variables was based on the literature and previous experience of this type of data. For details of the mixed effects models analysis see (Additional file 5). Where applicable, a Bonferroni adjustment was applied to the p-values from the survival analysis in order to correct for multiple testing.

\section{Results and discussion}

Increased CpG methylation of multiple Wnt antagonists during colorectal neoplastic progression

To gain systematic information regarding the epigenetic silencing of Wnt signalling during CRC progression, we selected a panel of 17 genes encoding Wnt signalling components for pyrosequencing (Additional file 1). We examined the DNA methylation of 134 CpG dinucleotides within promoter-CpG islands associated with these genes (full details of individual CpGs are listed in Additional file 4) in 264 matched normal, adenomatous or hyperplastic polyps and adenocarcinoma tissue samples obtained from 126 patients. As the data represent the different stages and time points along the progression of colorectal neoplasia, we analysed our data by using a $\mathrm{k}$-means clustering algorithm that clusters the trajectories of the matched pyrosequencing data points from the different tissue samples in individual patients based on the Calinski and Harabasz criterion [32]. This criterion revealed two main clusters with significantly different CpG patterns $(P<0.05$, Fisher's exact test) (Additional file $6)$, dependent on whether the genes encode Wnt antagonists or agonists (Figure 1).

The first of these clusters contains seven genes (SFRP1, SFRP2, SFRP5, DKK2, WIF1, WNT3A and SOX17) whose CpG methylation increased significantly from normal to adenoma $(P<0.001$, Wilcoxon signed rank test or paired $\mathrm{t}$-test depending on data distribution and false discovery rate adjusted for multiple testing (Additional file 7)): of these, six encode Wnt antagonists (SFRP1, SFRP2, SFRP5, $D K K 2$, WIF1 and SOX17) with only the Wnt antagonists SFRP1, SFRP2, WIF1 and DKK2 showing further significant increase in methylation from adenoma to carcinoma $(P<0.05$, Wilcoxon signed rank test or paired t-test depending on data distribution (Additional file 7)). This indicates a strong tendency for Wnt signalling antagonists to become hypermethylated during CRC progression, suggesting that the Wnt signalling levels may increase during the advancement of cancer. Interestingly, mixed effects models analysis of known mutations in three genes (APC, BRAF and KRAS) known to play an important role in colorectal neoplasia showed that most mutations occur at the normal to adenoma transition unlike hypermethylation of Wnt antagonists which continues to accumulate during the adenoma to carcinoma transition (Additional file 8). 


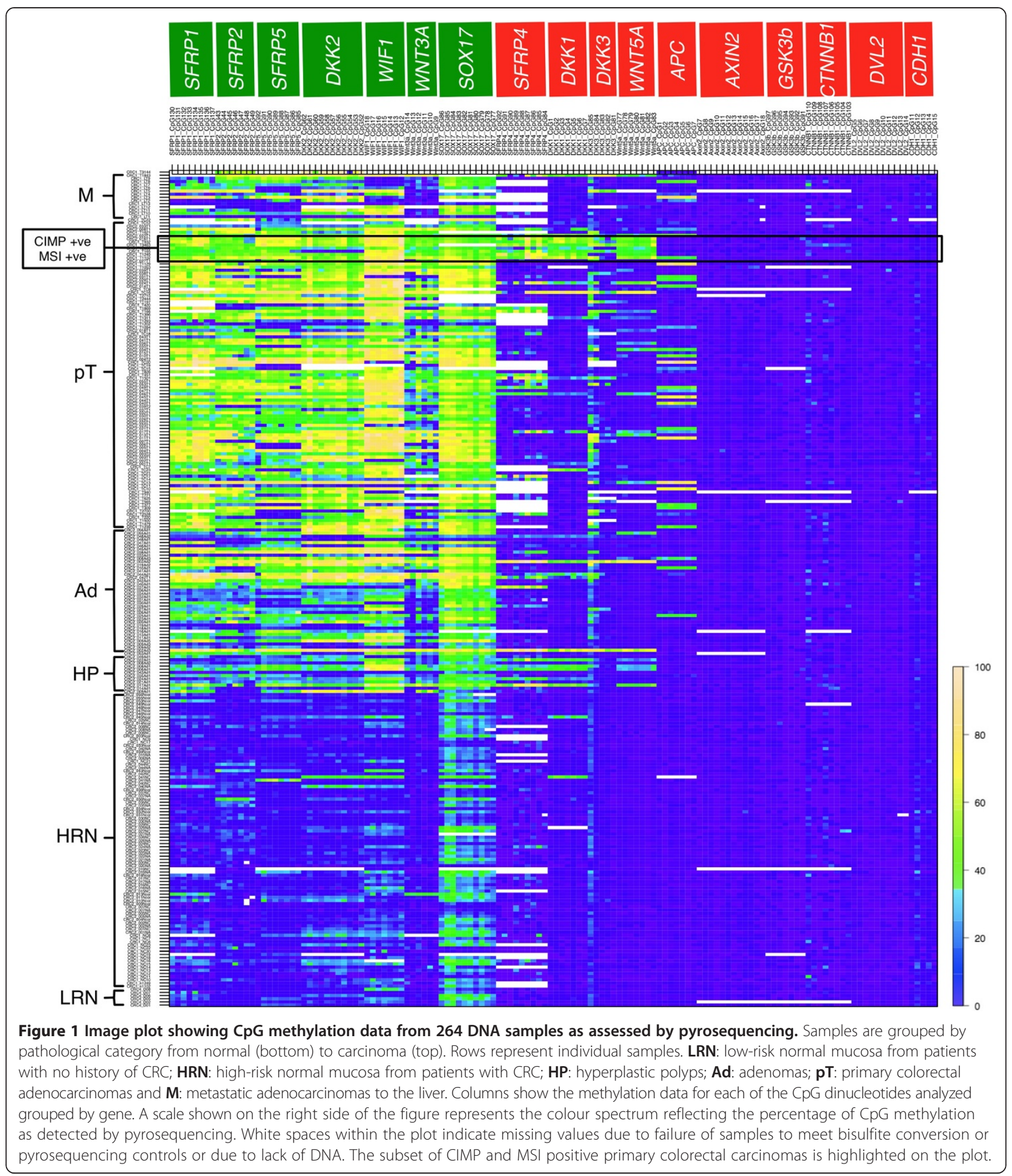

Slightly at odds with other members of the first cluster is the presence of WNT3A (encoding a Wnt ligand that triggers 'canonical' or $\beta$-catenin-dependent signalling), [33] which shows the same tendency towards promoter hypermethylation albeit not significantly at the adenoma to the carcinoma stage $(P=0.0678$, Wilcoxon signed rank test (Additional file 7)). This increase in methylation is somewhat unexpected as it suggests that this canonical Wnt ligand decreases during progression, although we have not shown this explicitly. We note that several other Wnt ligands such as WNT2, WNT10A and WNT6 are expressed at high levels in CRC 
samples, [34-37] which could substitute for the potentially decreasing Wnt3a in the activation of $\beta$-catenin.

The second cluster contains 10 genes (SFRP4, DKK1, DKK3, WNT5A, APC, AXIN2, GSK3b, CTNNB1, DVL2, $C D H 1)$ whose methylation is less frequent, and at lower levels. However, five of the genes in this cluster exhibit a moderate level of progressive CpG methylation, and thus form a distinct sub-group. This sub-group includes four genes that encode further Wnt antagonists (SFRP4, DKK1, $D K K 3, A P C)$. The fifth gene encodes WNT5A, a ligand that triggers $\beta$-catenin-independent ('non-canonical') signalling, which can be accompanied by an attenuation of $\beta$-catenin-dependent Wnt signalling [38]. The remaining five genes show no detectable promoter methylation, and thus form a second sub-group. This sub-group includes the two genes in our panel that encode positive Wnt signalling components, namely DVL2 and $\beta$-catenin. It also contains $A X I N 2$, a gene universally activated by $\beta-$ catenin during Wnt signalling, [39] which is as expected since this gene is strongly expressed during the progression of CRC [11] (see also below).

Interestingly, $A P C$ was amongst the subset of genes with a considerable tendency for hypermethylation in carcinomas (Figure 1). Hypermethylation of $A P C$ was present in carcinomas independently of whether or not the tumours already bear APC mutations (Additional file 9). Given that the great majority of $A P C$ mutations in CRC cause APC truncations that retain partial function (e.g. the binding to $\beta$-catenin), [40] this suggests that the observed hypermethylation of $A P C$ could cause epigenetic silencing and reduced expression of the mutant truncated APC. This accounts for a further reduction of APC function, beyond the level that caused initiation of tumorigenesis. In other words, epigenetic silencing of $A P C$ could be equivalent to epigenetic silencing of extracellular Wnt inhibitors, boosting the levels of Wnt signalling activity during CRC progression.

Our evidence supports the hypothesis that the selective and progressive hypermethylation of Wnt antagonists increases Wnt signalling during the progression of colorectal cancer, beyond the initial Wnt hyperactivation caused by the initiating mutations - typically $A P C$. An important implication is that Wnt signalling needs to be at least sustained, if not boosted, in order for adenomas to progress to colorectal carcinomas. This reinforces a previous conclusion that Wnt signalling is critical not only for the initiation of $\mathrm{CRC}$, but also for its progression [10]. The presence of Polycomb marks in regulatory regions of genes that are de novo methylated in cancer has been proposed to be the mechanism by which certain genes become preferentially hypermethylated in cancer [41-44]. The Wnt antagonists SFRP1, SFRP2, SFRP4, SFRP5, DKK1, DKK2, SOX17 and WIF1 have all been reported to be Polycomb target genes in human embryonic stem cells, embryonic fibroblasts, lymphoblasts and murine embryonic stem cells, $[45,46]$ raising the possibility that Polycomb-induced epigenetic silencing may be the underlying mechanism for the selective hypermethylation of these Wnt antagonists. However, CTNNB1 and AXIN2 have also been reported to be Polycomb target genes, $[41,45,47]$ but showed no detectable hypermethylation during colorectal neoplastic progression in our sample set, suggesting that factors in addition to the Polycomb determine whether or not the promoter of a Wnt gene becomes epigenetically silenced.

We have shown previously that CIMP correlates with the pattern of global CpG methylation and MSI status in CRC [14]. We have also reported that a small subset of the carcinomas, but none of the normal, hyperplastic polyp nor adenoma samples used in this study, are CIMP or MSI positive, [14] so we asked whether some of the observed hypermethylation correlated with the CIMP and/or MSI status of the corresponding carcinomas. Indeed, several loci showed correlation with CIMP positive state (Additional file 10) but only three the loci (SFRP4, DKK1 and WNT5A) showed significant correlation with both CIMP and MSI positive status (Figure 1; Additional file 10), suggesting that hypermethylation at these three loci may have been exacerbated by the MSI status of these carcinomas and that it may share a common mechanism leading to hypermethylation of the CIMP genes. Importantly though, the three loci also show a tendency for moderate hypermethylation amongst the remaining CIMP- and MSI-negative tumours (Figure 1). This reinforces the notion that these three genes belong to the sub-group of genes with a moderate tendency for hypermethylation during CRC progression.

\section{Correlation of Wnt antagonist hypermethylation with loss of gene expression}

To establish whether the observed DNA hypermethylation is functionally relevant, we examined the levels of gene expression of five of the Wnt antagonists (SFRP1, SFRP2, SFRP5, DKK2 and WIF1) with progressive hypermethylation during neoplastic development of CRC. To do this, we used quantitative RT-PCR on total RNA extracted from a subset of matched normal, hyperplastic polyps/adenomas and adenocarcinoma tissue samples and determine the expression fold-change of these five genes. We observed a significant negative correlation between the expression fold-change and the DNA methylation levels for SFRP1 $(r=-0.584, P<0.001$ Pearson correlation test), SFRP2 $(r=-0.340, P=0.032$ Pearson correlation test), SFRP5 $(r=-0.375, P=0.038$ Pearson correlation test) and WIF1 $(r=-0.384, P=0.048$ Pearson correlation test) (Figure 2). This parallels previous results, which revealed an overall decrease in SFRP1, SFRP2 and SFRP5 expression correlating with promoter 

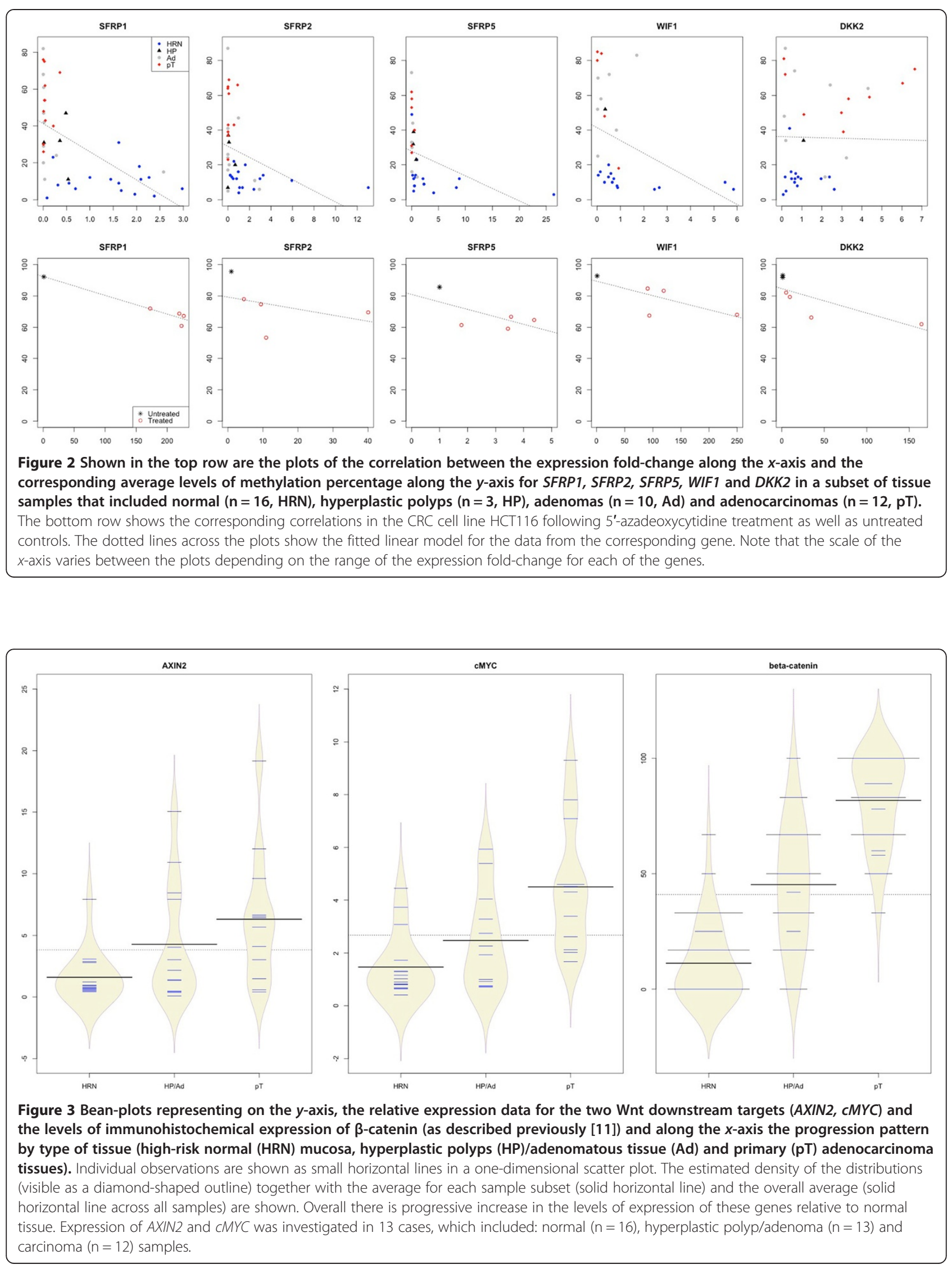
hypermethylation of these genes [12]. Only DKK2 (which is expressed at relatively low levels in the normal colorectal mucosa and whose methylation levels are low) showed no significant correlation between methylation and expression levels $(r=-0.16, P=0.36$, Pearson correlation test). Either, our analysis was not sensitive enough to detect such a correlation, or the hypermethylation of $D K K 2$ is simply a bystander effect, and functionally irrelevant.

To support the observed correlations between DNA methylation and expression levels in the tissue samples, we examined the effect of $5^{\prime}$-aza-2'-deoxycytidine (5-azaDC) treatment on the levels of DNA methylation associated with the same set of five genes (SFRP1, SFRP2, SFRP5, $D K K 2$ and WIF1) in the colorectal cancer cell line HCT116 (bearing an activating mutation of $\beta$-catenin). Untreated cells showed high levels of CpG methylation for each of the five genes, correlating with low levels or absent mRNA expression (Figure 2). However, 5-azaDC treatment not only decreased the levels of methylation, but also increased the corresponding levels of mRNA expression (Figure 2). Thus, the levels of Wnt antagonist expression depended in each case on de-methylation of their CpG islands. This provides strong evidence that the majority of the observed hypermethylation in tumours (Figure 1) is functionally relevant, reducing the expression of the linked genes.

\section{Hypermethylation of Wnt antagonists correlates with nuclear accumulation of $\beta$-catenin}

We have previously shown that, in the same set of matched tumour samples examined here for hypermethylation, the levels of nuclear $\beta$-catenin increase step-wise from normal tissues to hyperplastic polyps and adenomas to adenocarcinomas [11].

To confirm the functional relevance of the observed increases in the levels of nuclear $\beta$-catenin, we examined the expression levels of two well-established Wnt target genes, AXIN2 and $c-M Y C$. There was a significant increase in their levels of expression during colorectal neoplastic progression $(P=0.008$ and $P<0.001$ respectively, Wilcoxon signed rank test) (Figure 3), and for $c-M Y C$ this significantly and strongly correlated with the levels of nuclear $\beta$-catenin $(r=0.751, P<0.001$, Pearson correlation test).

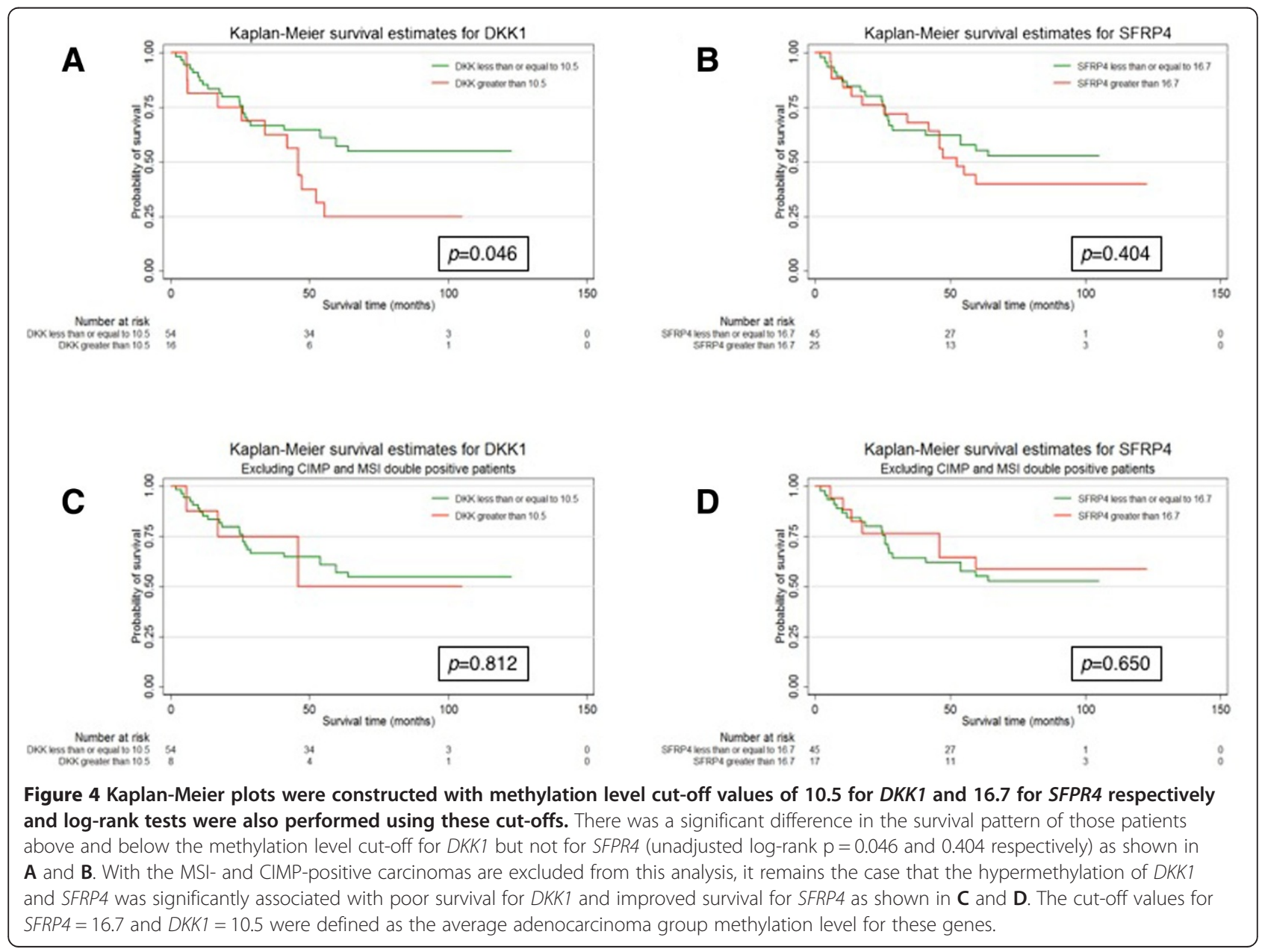


The expression levels of these two genes also correlated significantly with the methylation levels of SFRP1 $(r=0.456$, $P=0.003$ and $r=0.494, P=0.001$ respectively, Pearson correlation test) and SFRP2 $(r=0.448, P=0.003$ and $r=0.491$, $P=0.001$ respectively, Pearson correlation test). These results suggest that these SFRPs are the two functionally most relevant Wnt antagonists underlying the mechanism of progressive accumulation of nuclear $\beta$-catenin and increased Wnt target gene expression during CRC progression. Their epigenetic silencing could be one of the key factors driving the neoplastic progression in CRC.

\section{Correlation between hypermethylation of Wnt antagonists and patient survival}

To evaluate the association between methylation of the Wnt components and patient survival, we used the average DNA methylation of each gene and analysed them in this study as dichotamous variables using log-rank tests, and as continuous variables in univariable and multivariable Cox regression models. Only the methylation values relative to the adenocarcinoma samples were used. We had survival data available for only 70 patients with a median follow-up time of 59.3 months (range 2-122.3 months) during which 36 patients $(51.43 \%)$ died. In univariable Cox regression, DKK1 and SFRP4 methylation levels had similar hazard ratios of slightly greater than 1 , though neither result was significant after adjustment for multiple testing $(\mathrm{HR}=1.026$ and 1.006 and adjusted $P=0.280$ and 1.000 respectively), this could be due to the small number of patients included in the analysis. Despite these results, when included in multivariable Cox regression, increase in DKK1 methylation showed a significant association with poor prognosis (HR $=1.094, P=0.002)$ whilst increase in SFRP4 methylation showed a significant association with improved prognosis $(\mathrm{HR}=0.942, P=0.017)$. The directional change of the hazard ratio for SFRP4 between the univariable and multivariable Cox regression models is attributed to the adjustment for DKK1 and WNT5A in the multivariable model. After adjusting for the hazard of death associated with DKK1 and WNT5A, increases in SFRP4 methylation appear to be protective rather than hazardous, this unexpected finding could be due to the small sample size analysed and further studies are required to validate these findings. WNT5A was included in the multivariable Cox regression model as a covariate of interest but was not found to be significantly associated with survival.

To represent the data for DKK1 and SFPR4 graphically, Kaplan-Meier plots were constructed with methylation level cut-off values of 10.5 for $D K K 1$ and 16.7 for SFPR4 respectively (Figure $4 \mathrm{~A}$ and $\mathrm{B}$ ), and log-rank tests were also performed using these cut-offs. There was a significant difference in the survival pattern of those patients above and below the methylation level cut-off for $D K K 1$ but not for SFPR4 (unadjusted log-rank $P=0.046$ and 0.404 respectively).

Recall that both genes belong to the sub-group of moderately methylated genes, and that both are prone to hypermethylation in MSI- and CIMP-positive carcinomas (Figure 1). Therefore we repeated the survival analysis after excluding the MSI- and CIMP-positive carcinomas and this showed that the hypermethylation of $D K K 1$ and SFRP4 was no longer significantly associated with survival ((Figure $4 \mathrm{C}$ and D), (unadjusted log-rank $P=0.812$ and 0.650 respectively)). This suggests that the changes in survival patterns associated with hypermethylation of $D K K 1$ and SFRP4 are caused by their association with MSI and CIMP status.

\section{Conclusions}

Analysing the promoters of Wnt signalling antagonists in a large matched sample set of various stages of CRC showed that the frequency and levels of hypermethylation increased with neoplastic progression, in a progressive multistep pattern from normal epithelium to adenoma to adenocarcinoma. Therefore, DNA hypermethylation of the Wnt antagonists SFRP1, SFRP2, SFRP5, DKK2, WIF1 and SOX17 could provide useful biomarkers for early detection of CRC in screening studies involving DNA methylation, either in stool or plasma samples. Furthermore, two of the Wnt antagonists that are prone to methylation (DKK1 and SFRP4) appear to have prognostic significance, and so it may prove informative to assess their methylation status upon diagnosis of CRC.

\section{Additional files}

Additional file 1: Is a table with the summary of the Wnt signalling components included in our study. Each gene is included in one of two categories: active antagonist, and non-antagonists that are further subdivided into negative regulators, agonists or WNT coding proteins based on their known roles in Wnt signalling from the literature.

Additional file 2: Is a table containing the clinicopathological characteristics of patients.

Additional file 3: Is supplementary information of the methods used in the synthesis of complementary DNA (CDNA) by reverse transcription, quantitative PCR (qPCR) and cell treatment with 5-Aza-2'-Deoxycitidine.

Additional file 4: Is a table with the sequences of all Pyrosequencing primers and PCR conditions used.

Additional file 5: Is the analysis supplementary document. Additional file 6: Is a group of three figures representing the cluster analysis using $K m L$ package (k-means for longitudinal data), (A) Calinski\&Harabasz criterion highest score was two. (B) Mean trajectories of each cluster, $A$ in red and $B$ in green (0-LRN, 1-HRN, 2-hyperplastic polyps, 3-adenomatous polyps, 4-primary carcinoma, 5-metastatic adenocarcinoma). (C) Methylation percentages for each CpG island clustered according to Calinski\&Harabasz criterion (A in red, $B$ in green).

Additional file 7: Is a table with the results of the Wilcoxon signed rank test or paired t-test depending on data distribution and false discovery rate adjusted for multiple testing. 
Additional file 8: Includes two figures of the estimates from the linear mixed effect model for methylation (A) and logistic mixed effect model for mutations (B) through the neoplastic progression. All mutations are present by the adenoma stage while methylation gains continue to increase up to the carcinoma stage showing a considerable reduction at the metastasis stage.

Additional file 9: Is a table listing the APC mutations and LOH status of the samples used in this study.

Additional file 10: Is a table of the results of the point-biserial correlation test $r_{p b}$ value and $p$ value of the correlation between DNA methylation of each gene and MSI/MSI in primary tumours.

\section{Competing interests}

The authors declare that they have no competing interests.

\section{Authors' contributions}

AEKI and A-LS designed the study, interpreted the results and performed the experiments. AEKI, ST and SND performed the bioinformatic analyses. AEKI, EAC, NRH and TH-MH collected and provided the tissue specimen samples. KG and NRH collected the survival data. AEKI, MJA, A-LS, JDB, ST and MB contributed to the study design, provided material and drafting the manuscript. All authors read and approved the final manuscript.

\section{Acknowledgements}

We thank the Tissue Bank Facility in Addenbrooke's Hospital (funded through the NIHR Biomedical Research (entre) for their help with this work. A.L.S. was supported by the Fundacao para a Ciencia e Tecnologia (Portugal); A.I. by a Clinician Scientist Fellowship from Cancer Research UK (grant no C10112/A11388); M.B. by the Medical Research Council (U105192713) and by Cancer Research UK (grant no C7379/A8709).

\section{Author details}

${ }^{1}$ Department of Pathology, Division of Molecular Histopathology, University of Cambridge, Addenbrooke's Hospital, Hills Road, Cambridge CB2 2QQ, UK. ${ }^{2}$ Cambridge Clinical Trials Unit, Cambridge University Hospitals NHS Foundation Trust, Hills Road, Cambridge CB2 0QQ, UK. ${ }^{3}$ Cancer Research UK Cambridge Institute, Li Ka Shing Centre, Robinson Way, Cambridge CB2 ORE, UK. ${ }^{4}$ University of Edinburgh Division of Pathology, Edinburgh Cancer Research Centre, Institute of Genetics \& Molecular Medicine, Western General Hospital, Crewe Road South, Edinburgh EH4 2XR, UK. ${ }^{5}$ Cambridge Colorectal Unit, Box 201, Department of Surgery, Addenbrooke's Hospital, Hills Road, Cambridge CB2 2QQ, UK. ${ }^{6}$ Gastroenterology, Addenbrooke's Hospital, Hills Road, Cambridge CB2 2QQ, UK. ' University of Texas Health Science Center, 7979 Wurzbach Road, San Antonio, Texas 78229-3900, USA. ${ }^{8}$ MRC, Laboratory of Molecular Biology, Hills Road, Cambridge CB2 0QH, UK.

Received: 14 January 2014 Accepted: 22 November 2014 Published: 29 November 2014

\section{References}

1. Cancer Research UK, Bowel cancer mortality statistics. [http://ww. cancerresearchuk.org/cancer-info/cancerstats/types/bowel/http://www. cancerresearchuk.org/cancer-info/cancerstats/types/bowel/mortality/\#By]

2. Vogelstein $B$, Fearon ER, Hamilton SR, Kern SE, Preisinger AC, Leppert M, Nakamura Y, White R, Smits AM, Bos JL: Genetic alterations during colorectal-tumor development. N Engl J Med 1988, 319:525-532.

3. Jones PA, Laird PW: Cancer epigenetics comes of age. Nat Genet 1999, 21:163-167.

4. Beggs AD, Jones A, El-Bahrawy M, Abulafi M, Hodgson SV, Tomlinson IP: Whole-genome methylation analysis of benign and malignant colorectal tumours. J Pathol 2013, 229:697-704.

5. Morin PJ, Sparks AB, Korinek V, Barker N, Clevers H, Vogelstein B, Kinzler KW: Activation of beta-catenin-Tcf signaling in colon cancer by mutations in beta-catenin or APC. Science 1997, 275:1787-1790.

6. Ilyas M, Tomlinson IP, Rowan A, Pignatelli M, Bodmer WF: Beta-catenin mutations in cell lines established from human colorectal cancers. Proc Natl Acad Sci U S A 1997, 94:10330-10334.

7. Bienz M, Clevers H: Linking colorectal cancer to Wnt signaling. Cell 2000, 103:311-320.
8. van de Wetering M, Sancho E, Verweij C, de Lau W, Oving I, Hurlstone A, van der Horn K, Batlle E, Coudreuse D, Haramis AP, Tjon-Pon-Fong M, Moerer P, van den Born M, Soete G, Pals S, Eilers M, Medema R, Clevers H: The beta-catenin/TCF- 4 complex imposes a crypt progenitor phenotype on colorectal cancer cells. Cell 2002, 111:241-250.

9. Sansom OJ, Meniel VS, Muncan V, Phesse TJ, Wilkins JA, Reed KR, Vass JK Athineos D, Clevers H, Clarke AR: Myc deletion rescues Apc deficiency in the small intestine. Nature 2007, 446:676-679.

10. Scholer-Dahirel A, Schlabach MR, Loo A, Bagdasarian L, Meyer R, Guo R, Woolfenden S, Yu KK, Markovits J, Killary K, Sonkin D, Yao YM, Warmuth M, Sellers WR, Schlegel R, Stegmeier F, Mosher RE, McLaughlin ME: Maintenance of adenomatous polyposis coli (APC)-mutant colorectal cancer is dependent on Wnt/beta-catenin signaling. Proc Natl Acad SCi US A 2011, 108:17135-17140.

11. Metcalfe C, Ibrahim AE, Graeb M, de la Roche M, Schwarz-Romond T, Fiedler M, Winton DJ, Corfield A, Bienz M: Dvl2 promotes intestinal length and Neoplasia in the ApcMin mouse model for colorectal cancer. Cancer Res 2010, 70:6629-6638.

12. Suzuki $H$, Watkins DN, Jair KW, Schuebel KE, Markowitz SD, Chen WD, Pretlow TP, Yang B, Akiyama Y, Van Engeland M, Toyota M, Tokino T, Hinoda Y, Imai K, Herman JG, Baylin SB: Epigenetic inactivation of SFRP genes allows constitutive WNT signaling in colorectal cancer. Nat Genet 2004, 36:417-422.

13. Qi J, Zhu YQ, Luo J, Tao WH: Hypermethylation and expression regulation of secreted frizzled-related protein genes in colorectal tumor. World J Gastroenterol 2006, 12:7113-7117.

14. Ibrahim AE, Arends MJ, Silva AL, Wyllie AH, Greger L, Ito Y, Vowler SL, Huang TH, Tavare S, Murrell A, Brenton JD: Sequential DNA methylation changes are associated with DNMT3B overexpression in colorectal neoplastic progression. Gut 2011, 60:499-508.

15. Rawson JB, Manno M, Mrkonjic M, Daftary D, Dicks E, Buchanan DD, Younghusband HB, Parfrey PS, Young JP, Pollett A, Green RC, Gallinger S, McLaughlin JR, Knight JA, Bapat B: Promoter methylation of Wnt antagonists DKK1 and SFRP1 is associated with opposing tumor subtypes in two large populations of colorectal cancer patients. Carcinogenesis 2011, 32:741-747.

16. Taniguchi H, Yamamoto H, Hirata T, Miyamoto N, Oki M, Nosho K, Adachi Y, Endo T, Imai K, Shinomura Y: Frequent epigenetic inactivation of Wnt inhibitory factor-1 in human gastrointestinal cancers. Oncogene 2005, 24:7946-7952

17. Voorham QJ, Janssen J, Tijssen M, Snellenberg S, Mongera S, van Grieken NC, Grabsch H, Kliment M, Rembacken BJ, Mulder CJ, van Engeland M, Meijer GA, Steenbergen RD, Carvalho B: Promoter methylation of Wnt-antagonists in polypoid and nonpolypoid colorectal adenomas. BMC Cancer 2013, 13:603.

18. Veeck J, Dahl E: Targeting the Wnt pathway in cancer: the emerging role of Dickkopf-3. Biochim Biophys Acta 1825, 2012:18-28.

19. Sato H, Suzuki H, Toyota M, Nojima M, Maruyama R, Sasaki S, Takagi H, Sogabe Y, Sasaki Y, Idogawa M, Sonoda T, Mori M, Imai K, Tokino T, Shinomura Y: Frequent epigenetic inactivation of DICKKOPF family genes in human gastrointestinal tumors. Carcinogenesis 2007, 28:2459-2466.

20. Jiang X, Tan J, Li J, Kivimae S, Yang X, Zhuang L, Lee PL, Chan MT, Stanton LW, Liu ET, Cheyette BN, Yu Q: DACT3 is an epigenetic regulator of Wnt/beta-catenin signaling in colorectal cancer and is a therapeutic target of histone modifications. Cancer Cell 2008, 13:529-541.

21. Esteller M, Sparks A, Toyota M, Sanchez-Cespedes M, Capella G, Peinado MA, Gonzalez S, Tarafa G, Sidransky D, Meltzer SJ, Baylin SB, Herman JG: Analysis of adenomatous polyposis coli promoter hypermethylation in human cancer. Cancer Res 2000, 60:4366-4371.

22. Koinuma K, Yamashita Y, Liu W, Hatanaka H, Kurashina K, Wada T, Takada S, Kaneda R, Choi YL, Fujiwara SI, Miyakura Y, Nagai H, Mano H: Epigenetic silencing of AXIN2 in colorectal carcinoma with microsatellite instability. Oncogene 2006, 25:139-146.

23. Kamiyama H, Noda H, Takata O, Suzuki K, Kawamura Y, Konishi F: Promoter hypermethylation of tumor-related genes in peritoneal lavage and the prognosis of patients with colorectal cancer. J Surg Oncol 2009, 100:69-74

24. Zhang W, Glockner SC, Guo M, Machida EO, Wang DH, Easwaran H, Van Neste L, Herman JG, Schuebel KE, Watkins DN, Ahuja N, Baylin SB: Epigenetic inactivation of the canonical Wnt antagonist SRY-box containing gene 17 in colorectal cancer. Cancer Res 2008, 68:2764-2772. 
25. Pfaffl MW: A new mathematical model for relative quantification in real-time RT-PCR. Nucleic Acids Res 2001, 29:e45.

26. Ito $Y$, Koessler T, Ibrahim AE, Rai S, Vowler SL, Abu-Amero S, Silva AL, Maia AT, Huddleston JE, Uribe-Lewis S, Woodfine K, Jagodic M, Nativio R Dunning A, Moore G, Klenova E, Bingham S, Pharoah PD, Brenton JD, Beck S, Sandhu MS, Murrell A: Somatically acquired hypomethylation of IGF2 in breast and colorectal cancer. Hum Mol Genet 2008, 17:2633-2643.

27. Suraweera N, Robinson J, Volikos E, Guenther T, Talbot I, Tomlinson I, Silver A: Mutations within Wnt pathway genes in sporadic colorectal cancers and cell lines. Int J Cancer 2006, 119:1837-1842.

28. Cejas P, Lopez-Gomez M, Aguayo C, Madero R, de Castro CJ, Belda-Iniesta C, Barriuso J, Moreno Garcia V, Larrauri J, Lopez R, Casado E, Gonzalez-Baron M, Feliu J: KRAS mutations in primary colorectal cancer tumors and related metastases: a potential role in prediction of lung metastasis. PLOS ONE 2009, 4:e8199.

29. Genolini C, Falissard B: KmL: a package to cluster longitudinal data. Comput Methods Programs Biomed 2011, 104:e112-e121.

30. R Core Team: Vienna, Austria: R Foundation for Statistical Computing; 2012.

31. StataCorp S: Release 11. StataCorp LP, College Station, TX: Statistical Software; 2009.

32. Caliński T, Harabasz J: A dendrite method for cluster analysis. Communications in Statistics-Theory and Methods 1974, 3:1-27.

33. MacDonald BT, Tamai $\mathrm{K}$, He X: Wnt/beta-catenin signaling: components, mechanisms, and diseases. Dev Cell 2009, 17:9-26.

34. Park JK, Song JH, He TC, Nam SW, Lee JY, Park WS: Overexpression of Wnt-2 in colorectal cancers. Neoplasma 2009, 56:119-123.

35. Ma XR, Edmund Sim UH, Pauline B, Patricia L, Rahman J: Overexpression of WNT2 and TSG101 genes in colorectal carcinoma. Trop Biomed 2008, 25:46-57.

36. Le Floch N, Rivat C, De Wever O, Bruyneel E, Mareel M, Dale T, Gespach C: The proinvasive activity of Wnt-2 is mediated through a noncanonical Wnt pathway coupled to GSK-3beta and c-Jun/AP-1 signaling. FASEB J 2005, 19:144-146.

37. Kirikoshi H, Sekihara H, Katoh M: WNT10A and WNT6, clustered in human chromosome 2q35 region with head-to-tail manner, are strongly coexpressed in SW480 cells. Biochem Biophys Res Commun 2001, 283:798-805.

38. Mikels AJ, Nusse R: Purified Wnt5a protein activates or inhibits beta-catenin-TCF signaling depending on receptor context. PLOS Biol 2006, 4:e115.

39. Lustig B, Jerchow B, Sachs M, Weiler S, Pietsch T, Karsten U, van de Wetering M, Clevers H, Schlag PM, Birchmeier W, Behrens J: Negative feedback loop of Wnt signaling through upregulation of conductin/ axin2 in colorectal and liver tumors. Mol Cell Biol 2002, 22:1184-1193.

40. Albuquerque $C$, Breukel $C$, van der Luijt R, Fidalgo P, Lage P, Slors FJ, Leitao CN, Fodde R, Smits R: The 'just-right' signaling model: APC somatic mutations are selected based on a specific level of activation of the beta-catenin signaling cascade. Hum Mol Genet 2002, 11:1549-1560.

41. Schlesinger $Y$, Straussman R, Keshet I, Farkash S, Hecht M, Zimmerman J, Eden E, Yakhini Z, Ben-Shushan E, Reubinoff BE, Bergman Y, Simon I, Cedar H: Polycomb-mediated methylation on Lys 27 of histone $\mathrm{H} 3$ pre-marks genes for de novo methylation in cancer. Nat Genet 2007, 39:232-236.

42. Gal-Yam EN, Egger G, Iniguez L, Holster H, Einarsson S, Zhang X, Lin JC, Liang $G$, Jones PA, Tanay A: Frequent switching of Polycomb repressive marks and DNA hypermethylation in the PC3 prostate cancer cell line. Proc Natl Acad Sci U S A 2008, 105:12979-12984.

43. Ohm JE, McGarvey KM, Yu X, Cheng L, Schuebel KE, Cope L, Mohammad HP, Chen W, Daniel VC, Yu W, Berman DM, Jenuwein T, Pruitt K, Sharkis SJ, Watkins DN, Herman JG, Baylin SB: A stem cell-like chromatin pattern may predispose tumor suppressor genes to DNA hypermethylation and heritable silencing. Nat Genet 2007, 39:237-242.

44. Widschwendter M, Fiegl H, Egle D, Mueller-Holzner E, Spizzo G, Marth C, Weisenberger DJ, Campan M, Young J, Jacobs I, Laird PW: Epigenetic stem cell signature in cancer. Nat Genet 2007, 39:157-158.

45. Bracken AP, Dietrich N, Pasini D, Hansen KH, Helin K: Genome-wide mapping of Polycomb target genes unravels their roles in cell fate transitions. Genes Dev 2006, 20:1123-1136.
46. Lee $\mathrm{TI}$, Jenner RG, Boyer LA, Guenther MG, Levine SS, Kumar RM, Chevalier B, Johnstone SE, Cole MF, Isono K, Koseki H, Fuchikami T, Abe K, Murray HL, Zucker JP, Yuan B, Bell GW, Herbolsheimer E, Hannett NM, Sun K, Odom DT, Otte AP, Volkert TL, Bartel DP, Melton DA, Gifford DK, Jaenisch R, Young RA: Control of developmental regulators by Polycomb in human embryonic stem cells. Cell 2006, 125:301-313.

47. Boyer LA, Plath K, Zeitlinger J, Brambrink T, Medeiros LA, Lee TI, Levine SS, Wernig M, Tajonar A, Ray MK, Bell GW, Otte AP, Vidal M, Gifford DK, Young $R A$, Jaenisch R: Polycomb complexes repress developmental regulators in murine embryonic stem cells. Nature 2006, 441:349-353.

doi:10.1186/1471-2407-14-891

Cite this article as: Silva et al:: Boosting Wnt activity during colorectal cancer progression through selective hypermethylation of Wnt signaling antagonists. BMC Cancer 2014 14:891.

\section{Submit your next manuscript to BioMed Central and take full advantage of:}

- Convenient online submission

- Thorough peer review

- No space constraints or color figure charges

- Immediate publication on acceptance

- Inclusion in PubMed, CAS, Scopus and Google Scholar

- Research which is freely available for redistribution

Submit your manuscript at www.biomedcentral.com/submit
C Biomed Central 